\title{
Massive retrosternal goitre presenting with hypertension
}

\author{
M.P. HOLDEN, G. H. WO O LER, and M. I. I ONESCU \\ Department of Cardio-thoracic Surgery, the General Infirmary at Leeds and the University of Leeds, \\ Yorkshire
}

A patient presented to her doctor with dyspnoea on exertion. Hypertension was diagnosed and she was subsequently found to have a large retrosternal goitre. The blood pressure returned to normal after the tumour had been removed. To our knowledge no such case has previously been reported. Early removal of mediastinal tumours is advocated.

Patients with superior mediastinal tumours usually present with symptoms due to compression of adjacent organs, unless they are hormone-secreting tumours.

This case is described in order to draw attention to the very unusual occurrence of systemic hypertension due to outside compression of the aortic arch without concomitant obstruction of the venous return, and to emphasize the necessity of surgical removal of mediastinal tumours.

\section{CASE REPORT}

An obese West Indian woman aged 38 years presented in 1970 to her local physician with dyspnoea on exertion and occasional ankle oedema. The arterial blood pressure was $230 / 130 \mathrm{~mm}$ mercury which fell

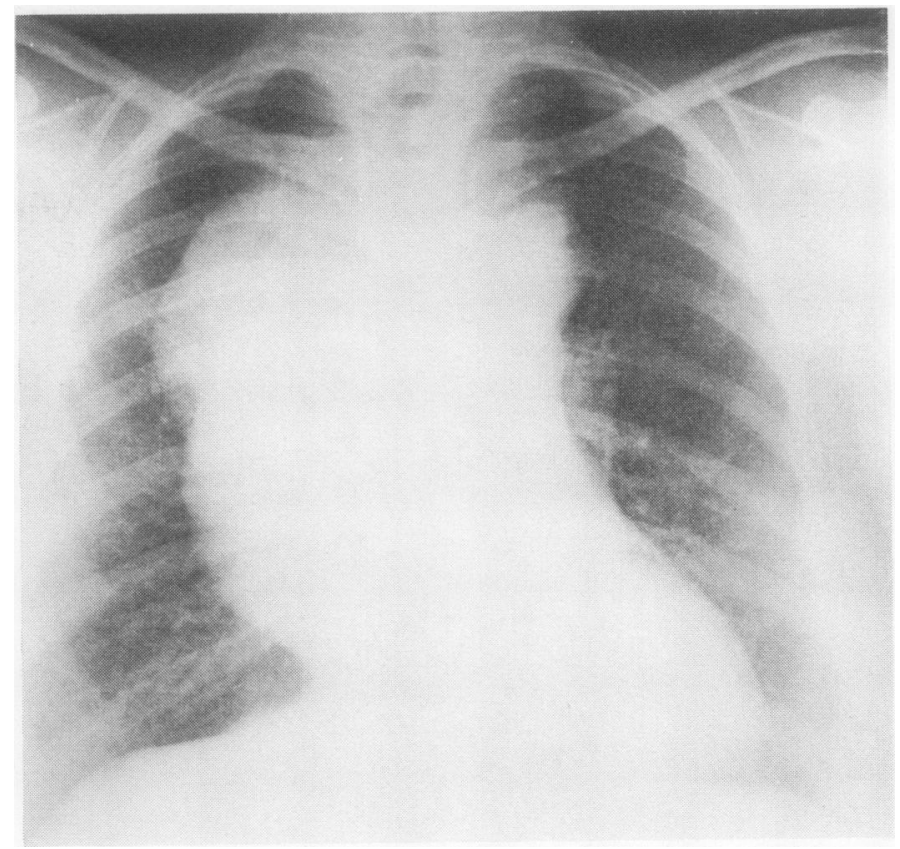

FIG. 1. Postero-anterior chest radiograph showing a considerably widened mediastinal shadow. The trachea is displaced to the right and the aortic knuckle to the left. 
to $140 / 90 \mathrm{mmHg}$ on treatment with methyldopa and bendrofluazide.

A cervical thyroidectomy had been performed in 1954 in the West Indies for nodular colloid goitre. Six years later in England a routine chest radiograph revealed a superior mediastinal tumour which concentrated ${ }^{131} \mathrm{I}$. It was decided not to remove it.

On admission in September 1971 the patient was depressed and withdrawn. The radial pulses were equal and regular and of good volume. The femoral pulses were equal and not delayed. The blood pressure was $150 / 90 \mathrm{mmHg}$ in both arms (it began to rise as soon as the methyldopa was reduced). The jugular venous pressure at $45^{\circ}$ was not raised. The apex beat was in the sixth intercostal space at the anterior axillary line. The blood urea was $70 \mathrm{mg} / 100 \mathrm{ml}$ with normal blood electrolytes.

The chest radiograph (Fig. 1) showed considerable widening of the mediastinum. A retrograde ascending aortogram was performed (Fig. 2) and this demonstrated compression of the aortic arch which was also displaced downwards and to the left. No coarctation was seen. The electrocardiogram suggested minimal left ventricular hypertrophy. The urine contained protein, abundant pus cells, and Klebsiella organisms. A barium swallow was normal.
OPERATION (13 Sept. 71) Through a right thoracotomy over the sixth rib an enormous tumour filling half the right pleural cavity was found. It had a thin capsule through which were passing many venous channels to open into the superior vena cava which was stretched and pushed out almost to the lateral chest wall.

The innominate vein could not be identified. Most of the tumour was extending into the right chest as far as the paravertebral gutter. Passing in front of the great arteries it extended along the left side of the trachea into the neck. The aortic arch was pushed downwards by the tumour as it entered the left chest.

The attachments of the capsule were divided from the root of the neck. When the extensions into the left chest were divided a considerable amount of venous bleeding occurred, following which the arterial blood pressure dropped to $60 \mathrm{mmHg}$ systolic and remained so for about five minutes. The mass was removed.

The postoperative period was complicated by a recurrence of the Klebsiella urinary tract infection and acute renal failure. During the period of anuria the blood urea rose to $210 \mathrm{mg} / 100 \mathrm{ml}$ blood. With conservative treatment the urea had returned to $38 \mathrm{mg} / 100 \mathrm{ml}$ within 14 days.

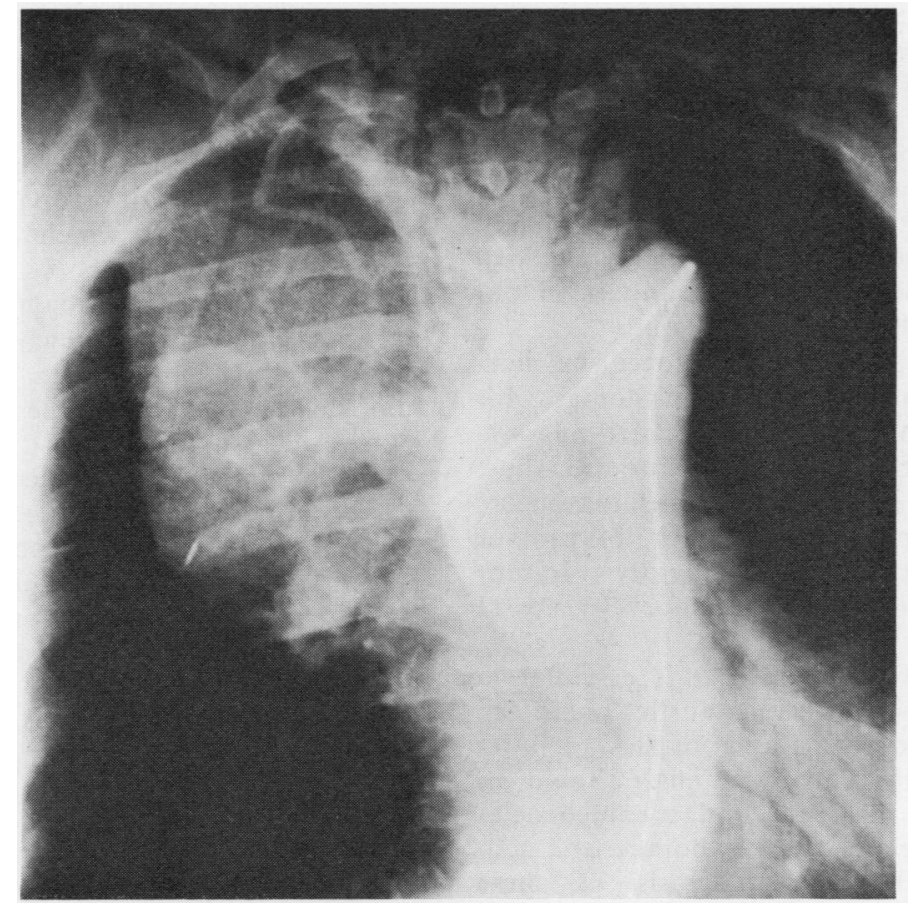

FIG. 2. Postero-anterior view of an angiogram. Contrast material had been injected in the ascending aorta. The deviation to the right of the trachea is clearly seen. The right innominate artery is also displaced to the right. The distal part of the ascending aorta as well as the artic arch are compressed and displaced downwards and to the left. 
The arterial blood pressure in both arms has remained at $130 / 80 \mathrm{mmHg}$ for four months without further medical treatment. Mentally the patient is alert and no longer depressed.

Histology of the removed tumour, which weighed $800 \mathrm{~g}$, demonstrated nodular colloid goitre.

\section{DISCUSSION}

The majority of intrathoracic goitres originate in the neck and extend into the mediastinum, carrying their cervical vascular attachments with them. The so-called primary intrathoracic goitres, which develop presumably from heteropic thyroid tissue in the mediastinum, are rare and derive their blood supply from intrathoracic vessels or from both thoracic and cervical vessels (Wychulis, Payne, Clagett, and Woolner, 1971).

Tumours of the superior mediastinum produce symptoms due to compression of adjacent structures in an anatomical region containing numerous viscera surrounded by an almost rigid skeleton. The symptoms are venous engorgement of the head and arms, dysphagia, cough, pain or voice changes.

Compression of the aorta associated with systemic arterial hypertension is unusual. This has not previously been described in reports by Witz, Gillet, Miech, and Weiss (1967) and Tala and Maamies (1967), describing 90 patients with intrathoracic goitres during a period of 21 years, nor by Wychulis et al. (1971), reporting on 56 patients. None of the previous 21 patients who underwent removal of superior mediastinal tumours in our department had arterial hypertension.

Very rarely symptoms are produced by hormone-secreting tumours. Neuroblastomas, for example, arise from the sympathetic nervous system and can produce adrenaline or noradrenaline, thereby introducing hypertension which disappears when the tumour is removed. However, this tumour is highly malignant and grows rapidly. In our patient such a possibility was excluded by the 11 years' history.

In the preoperative diagnosis it is essential to exclude the possibility of an aortic aneurysm because this requires heart-lung bypass facilities for removal. A differential diagnosis should be made from neural tumours and meningocoeles because they require a combined thoracic and neurosurgical approach. The diagnosis of these lesions can be confirmed by the demonstration of neural foraminal erosion of the vertebra in the former and pulsation of the paravertebral tumour in the latter (Wychulis et al., 1971). Such preoperative diagnostic procedures as needle biopsy or mediastinoscopy have little value and are exceedingly dangerous.

If the retrosternal goitre is small a cervical collar incision is advocated so that the vascular attachment in the neck can be ligated easily. If further exposure is required the sternum can be divided partially or completely. With larger tumours a thoracic approach is required and, as most of them extend into the right chest, a right thoracotomy is advisable. It is debatable in our case whether a median sternotomy would have facilitated removal of the tumour which also extended into the left chest. Horizontal division of the ster:uum might have been the most satisfactory procedure to extend the right thoracotomy.

The operative mortality for superior mediastinal tumours is low $-1.8 \%$ (Oldham and Sabiston, 1967). The longer they remain in situ the more likely are symptoms from compression of adjacent viscera, and the more difficult is removal, even if benign, with a consequent increase in morbidity and mortality.

It is assumed that the cause of the hypertension was compression of the aortic arch distal to the origin of the left subclavian artery, or interference with the baroceptor function in the aortic arch.

\section{CONCLUSIONS}

1. Arterial hypertension presenting as a physical sign is very unusual in patients with superior mediastinal tumours which are not neuroblastomas.

2. In the preoperative diagnosis it is only important to exclude aortic aneurysm and neurological tumours which require, in the former, cardiopulmonary bypass and in the latter, a thoracic and neurosurgical approach.

3. Tumours in the mediastinum should be removed surgically, if possible as soon as they are diagnosed, because they continue to grow even if benign in nature and, due to the density of anatomical structures in this region, the morbidity and mortality of an otherwise safe surgical procedure increase considerably.

\section{REFERENCES}

Oldham, H. N. Jr., and Sabiston, D. C. Jr. (1967). Primary N tumours and cysts of the mediastinum. Monogr. surg. $\sigma$ Sci., 4, 243.

Tala, P., and Maamies, T. (1967). Intrathoracic goitreexperiences in surgical treatment of 90 intrathoracic $\bar{D}$ goitres during 21 years. Ann. Chir. Gynaec. Fenn., 56, 211. ?

Witz, J. P., Gillet, M., Miech, G., and Weiss, A. G. (1967). T Plunging intrathoracic goitres. J. Chir. (Paris), 93, 429.

Wychulis, A. R., Payne, W., Clagett, O. T., and Woolner, $\overrightarrow{\mathscr{D}}$ L. B. (1971). Surgical treatment of mediastinal tumours $\frac{\rho}{d}$ -40 years' experience.J. thorac. cardiovasc. Surg., 62, 379. Q 